\title{
Reasons for admission and neonatal outcome in the neonatal care unit of a tertiary care hospital in Addis Ababa: a prospective study
}

This article was published in the following Dove Press journal:

Research and Reports in Neonatology

18 March 2016

Number of times this article has been viewed

\section{Atnafu Mekonnen Tekleab' \\ Gesit Metaferia Amaru' \\ Yemisrach Abeje Tefera ${ }^{2}$ \\ 'Department of Pediatrics and Child Health, ${ }^{2}$ Department of Public Health, St Paul's Hospital Millennium Medical College, Addis Ababa, Ethiopia}

Video abstract

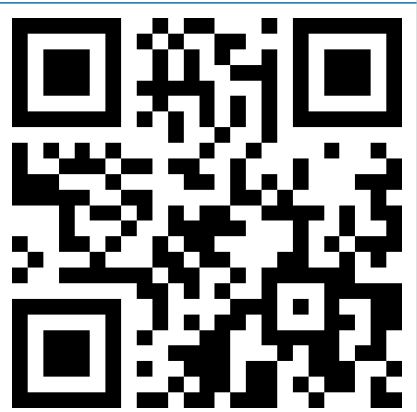

Point your SmartPhone at the code above. If you have a QR code reader the video abstract will appear. Or use: http://youtu.be/F6rDnmpSCr8
Correspondence: Atnafu Mekonnen Tekleab

Department of Pediatrics and Child Health, St Paul's Hospital Millennium Medical College, PO Box I27I,

Addis Ababa, Ethiopia

Tel +25 I 9 I I 34660 I

Email atnemekonnen@yahoo.com
Background: The neonatal mortality rate in Ethiopia remains greater than 35 per 1,000 live births. Hence, identifying the reasons for neonatal admission and mortality in a hospital setting is crucial to improve the quality of existing practices in the hospital. The objective of this study was to describe the reasons for admission and the magnitude of neonatal mortality in the neonatal care unit of St Paul's Hospital Millennium Medical College.

Methods and subjects: A prospective cohort study was conducted. A total of 216 neonates who were admitted to the neonatal care unit of St Paul's Hospital Millennium Medical College from March 1, 2015, to May 31, 2015, were included in this study. Data fields, determined prospectively, were collected by monitoring the neonates until discharge or death. The independent variables were demographic, obstetric, and clinical characteristics, while the dependent variable was neonatal mortality. Data were analyzed using simple frequencies, odds ratio, and finally binary logistic regression analysis for mortality outcome.

Results: The most common primary diagnoses at admission to the neonatal care unit were prematurity with respiratory problem (36.6\%), neonatal sepsis $(22.7 \%)$, and asphyxia (16.2\%). Out of the 216 neonates studied, 50 (23.2\%) died. High case fatality was observed among neonates with the diagnosis of prematurity with respiratory problem $(40.5 \%)$ and asphyxia $(40.0 \%)$. Under multivariate analysis, diagnosis of asphyxia was an independent predictor of mortality (adjusted odds ratio $=5.817 ; 95 \%$ confidence interval: $1.611-20.977$ ), while gestational age above the mean of the study population (36.6 weeks) was protective of mortality (adjusted odds ratio $=0.683 ; 95 \%$ confidence interval: $0.588-0.795$ ).

Conclusion: Nearly a quarter of admitted neonates died. This study identified asphyxia and prematurity as major causes of admission and mortality. Emphasis has to be given to prevent asphyxia and to improve the survival of preterm babies.

Keywords: neonate, admission, death, Ethiopia, neonatal outcome, hospital, Addis Ababa

\section{Introduction}

Over the past few years, there has been a decline in neonatal mortality rate. Approximately 4 million neonatal deaths were reported in $2005 .{ }^{1}$ However, 3.1 million and 2.9 million neonatal deaths were reported in 2010 and 2014, respectively. ${ }^{2,3}$ Despite a steady decline, the decline in neonatal mortality is not satisfactory and is slower than the reduction in overall child mortality, particularly in African countries. ${ }^{3}$

Most of the neonatal deaths occur in developing countries particularly in subSaharan African and south central Asian countries. Despite improvements over the past decade, Ethiopia's current neonatal mortality rate is one of the highest in the world. ${ }^{4}$ Neonatal mortality comprises a significant proportion of the under-five mortality in 
the country. Forty percent of the under-five mortality in the country is attributable to neonatal mortality. ${ }^{5}$ Hence, reducing the neonatal mortality rate is pivotal to reducing under-five mortality in the country.

Improving the quality of neonatal care provided at facility level is one way to decrease neonatal mortality. Quality improvement of neonatal care service can be achieved by improving the skills and knowledge of health care provider in addition to availing them with the equipment and resources required for quality care..$^{6,7}$

Hence, evaluating the causes of neonatal morbidity and mortality at facility level is an essential step toward improving the quality of existing practices. Despite the scarcity of information on these factors in Ethiopia, this study aimed to describe the characteristics of the neonates attended in the neonatal care unit of St Paul's Hospital Millennium Medical College (SPHMMC) and to study the magnitude of neonatal mortality in the unit.

\section{Methods and subjects}

A prospective cohort study was conducted in the neonatal care unit of SPHMMC, and data were collected from March 1, 2015, to May 31, 2015. SPHMMC is a public teaching hospital located in Addis Ababa, Ethiopia. The hospital has a neonatal care unit, which has been functional over the past 6 years. The neonatal care unit provides service for both inborn and outborn babies. The unit has facilities for resuscitation, incubators, radiant warmer, phototherapy unit, and exchange transfusion equipments. The unit lacks facilities for blood gas analysis, mechanical ventilation, patient monitor, perfusers, and parenteral nutrition. The unit provides service 24-hours a day. Nurses, intern doctors, pediatric resident doctors, and pediatricians work in this unit. Also, radiologic investigations, including ultrasound, computed tomography scan, and X-ray, are available in the hospital as are laboratory tests (including hematological, biochemical, and body fluid analyses).

For the study of the magnitude of neonatal mortality in the unit, the calculated sample size was 216 neonates. The assumptions made were $95 \%$ confidence interval (CI), $4 \%$ margin of error, and $10 \%$ mortality prevalence in the unit. Assuming 5\% dropout rate, the calculated sample size became 227 neonates. The $10 \%$ mortality prevalence that was used to calculate the sample size was obtained from the mortality report of the unit for the previous year preceding this study.

Before conducting the study, the authors reviewed the preceding year's monthly report of admission in the neonatal care unit and found no observed variation in the pattern of admission diagnosis and demographic characteristics.

All sick neonates who were admitted to the neonatal care unit of the hospital between March and May 2015 consecutively were included in this study. Study subjects were selected by trained pediatric residents. Those neonates who were admitted for observation or who were discharged well in $<24$ hours of admission were excluded from the study. All deaths after admission were also included.

Obstetric and demographic data were obtained by interviewing the parent or caregiver or by looking at the referral record at the time of admission. This part of the questionnaire was translated from English to the local Amharic language and then from local the Amharic language to English. Clinical data on the neonates were collected after conducting clinical evaluation and reviewing the laboratory test results.

A structured questionnaire was developed and used to collect data after it was pretested. The questionnaire contained information related to obstetrics, antenatal care (ANC) visit, age at admission, sex, gestational age, Apgar score, admission diagnosis, weight of the neonate, duration of hospital stay, need of ventilator support, and neonatal outcome.

Two pediatric residents and a pediatrician collected the data after being trained for half a day. The training included how to conduct interview, questionnaire content, how to measure weight, and about the operational definitions of the research. Admission diagnosis and outcome of the neonate were assessed by the data collectors as a part of the management of the neonate. During data collection, each neonate was monitored until discharge or death.

A final assessment of admission diagnosis and cause of death was set by the pediatrician after conducting the necessary laboratory investigation. A data collection guideline was prepared and was used during the data collection procedure. There was no change in the management guideline of the neonatal care unit for the purpose of this research.

Weight was measured during admission using digital infant weighing scale (seca gmbh \& co., Hamburg, Germany), which was placed on a fixed and leveled couch. Every time, before placing the baby on the scale, the data collectors adjusted the weighing scale to zero reading. Babies were weighed naked, and the weight was recorded to the nearest $0.05 \mathrm{~kg}$.

Gestational age of the baby was assessed using the last menstrual period. When the last menstrual period was not reliable or unknown, gestational age was determined using the New Ballard Score (scoring system used to assess the gestational maturity of a neonate). ${ }^{8}$ Primary diagnosis was defined 
as the main reason for admitting the neonate. Comorbid conditions were considered as secondary diagnosis. Prematurity was defined as live born neonate delivered before 37 weeks. Hypothermia was defined as body temperature $<36.5^{\circ} \mathrm{C}$ measured in the armpit during admission. A small for gestational age infant was defined as baby having a birth weight below the tenth percentile for its gestational age and sex using the Denver reference curve. Birth asphyxia was diagnosed when all of the following criteria were present: 1) persistence of an Apgar score of 0-3 for $>5$ minutes, 2) neonatal neurologic sequelae (eg, seizures, coma, and hypotonia), and 3) multiple organ involvement (eg, kidney, lungs, liver, heart, and intestines). ${ }^{9}$ Respiratory distress was diagnosed based on the clinical signs and radiologic findings. ${ }^{10}$ Sepsis was diagnosed based on the clinical findings and/or positive culture report. Hyperbilirubinemia was being managed according to the recommendation by the American Academy of Pediatrics. ${ }^{11}$

Data were analyzed using Statistical Package for the Social Sciences Version 20.0 software for windows. Univariate analysis was used to describe the frequency distribution of each of the variables mentioned earlier. Bivariate analysis was used to obtain unadjusted odds ratios and 95\% CIs for the outcome of neonatal mortality. Statistical significance was established when the $P$-value was $<0.05$. Finally, binary logistic regression analysis was used to establish significant associations in neonatal mortality.

Ethical approval was obtained from the Institutional Review Board of SPHMMC. Written consent was obtained from the attendant or parent of each baby, and no parent or attendant refused the consent.

\section{Results}

In our study, data were collected from 227 neonates, but only 216 neonates were included in the analysis. Of the 227 neonates, 163 were discharged when their condition improved, 50 died, eleven went against medical advice, and three referred to another hospital after their primary reason for admission was managed in the unit. In the data analysis, the three neonates who were referred to another hospital were treated as if they were discharged when their condition improved. The eleven neonates who went against medical advice were excluded from the data analysis since their outcome was not ascertained.

\section{Characteristics of the neonates during admission}

Of the 216 neonates, 132 (61.1\%) were male and 177 (81.9\%) were inborn. One hundred fourteen $(52.8 \%)$ were admitted within the first hour of age. One hundred ninety $(88.0 \%)$ were singleton, and the remaining were twins. Modes of delivery were spontaneous vaginal delivery $(55.6 \%)$, cesarean section (38.4\%), and operative vaginal delivery (6\%). Eighty-six $(39.8 \%)$ were born preterm (at gestational age $<37$ completed weeks) with $121(56.0 \%)$ at term and nine (4.2\%) at postterm gestation. One hundred eighty-four (85.2\%) were of appropriate weight for gestational age. The mean gestational age was 36.6 (standard deviation 3.8) weeks. One hundred nine $(50.5 \%)$ weighed $\geq 2,500 \mathrm{~g}$. Only five $(2.3 \%)$ neonates weighed $<1,000 \mathrm{~g}$ during admission. The mean duration of stay in the unit was 7.3 days.

One hundred nine $(50.5 \%)$ mothers were younger than 25 years, and 203 (94.0\%) were married. Fifty-six (25.9\%) were illiterate, and 17 (7.9\%) had attended higher education. Two hundred ten $(97.2 \%)$ received ANC during pregnancy. Of those who received ANC, 78 (37.1\%) mothers had more than three ANC visits, and the remaining 132 (62.9\%) mothers had up to three ANC visits. Ninety-two (42.6\%) mothers had obstetrical complication during pregnancy. The main complications observed were preeclampsia $(25 \%)$ and chorioamnionitis (30.4\%). Prelabour rupture of membranes was observed in $48(22.2 \%)$ mothers. Antenatal human immunodeficiency virus (HIV) testing was done in 107 (49.5\%) mothers. Five (4.7\%) of them were positive for HIV antibodies.

\section{Reasons for admission}

The most common primary diagnoses during admission to the neonatal care unit were prematurity with respiratory problem (36.6\%), neonatal sepsis (22.7\%), and asphyxia (16.2\%). These three conditions comprised $75.5 \%$ of the causes for admission, and the remaining reasons for admission were Meconium Aspiration Syndrome (13.9\%), hyperbilirubinemia (6.0\%), and other conditions (4.6\%). Hypothermia was diagnosed as comorbid illness in $60.6 \%$ of the neonates during admission.

\section{Neonatal outcome}

Of the 216 neonates, $50(23.1 \%)$ died in the neonatal unit, and the remaining 166 (76.9\%) were discharged when their condition improved. The diagnosis of prematurity with respiratory problem had a $40.5 \%$ case fatality rate with $40 \%$ for perinatal asphyxia. Thirty-six $(72 \%)$ of the 50 neonates who died had admission weight $<2,500 \mathrm{~g}$. Four $(80 \%)$ of the five neonates weighing $<1,000 \mathrm{~g}$ and $18(58.1 \%)$ of the 31 neonates $(58.1 \%)$ weighing between $1,000 \mathrm{~g}$ and $1,499 \mathrm{~g}$ died. Three $(9.4 \%)$ of the 32 small for gestational age neonates and $47(25.5 \%)$ of the 184 appropriate for gestational age 
neonates died. Three neonates whose gestational age was $<28$ weeks died. Of the 21 neonates whose gestational age was between 28 weeks and 31 weeks, 14 (66.7\%) died. Asphyxia was diagnosed in 35 neonates with 14 (40.0\%) deaths.

Prematurity with respiratory problem and asphyxia were the major causes of deaths $(64 \%$ and $28 \%$ of the deaths, respectively; Table 1). First-minute and fifth-minute Apgar scores were $<7$ for $79.5 \%$ and $56.8 \%$ of the deaths, respectively. The mothers of $92.0 \%$ of the neonates who died received $\mathrm{ANC}$, and the number of $\mathrm{ANC}$ visit was $<4$ for $80.4 \%$ of the deaths. Sixty percent of of the patients/babies who died (30 of the 50 deaths) were admitted to the neonatal unit within the first hour of age. Twelve (24.0\%) of the 50 deaths occurred within 1 day of admission and 34 (68\%) deaths occurred within 3 days of admission. Inborn neonates accounted $86.0 \%$ of the deaths.

Although ventilator was not available in the unit, the pediatrician who was responsible in treating the neonates recommended ventilator support for $45(90 \%)$ of the 50 neonates prior to their deaths.

Table I Neonatal characteristics by mortality, SPHMMC, June $2015(n=216)$

\begin{tabular}{|c|c|c|c|c|}
\hline Characteristics & $\begin{array}{l}\text { Total } \\
\text { number (\%) }\end{array}$ & $\begin{array}{l}\text { Case } \\
\text { fatality, } \\
\text { n (\%) }\end{array}$ & $\begin{array}{l}\text { Proportion } \\
\text { of deaths } \\
(\%)\end{array}$ & $P$-value ${ }^{a}$ \\
\hline \multicolumn{5}{|l|}{ Admission diagnosis } \\
\hline Prematurity & $79(36.6)$ & $32(40.5)$ & 64.0 & 0.000 \\
\hline Sepsis & $49(22.7)$ & $2(4.1)$ & 4.0 & \\
\hline Asphyxia & $35(16.2)$ & $14(40.0)$ & 28.0 & \\
\hline Hyperbilirubinemia & $13(6.0)$ & I (7.7) & 2.0 & \\
\hline MAS & $30(13.9)$ & I (3.3) & 2.0 & \\
\hline Other conditions & $10(4.6)$ & $0(0.0)$ & 0.0 & \\
\hline \multicolumn{5}{|l|}{ Admission weight } \\
\hline$\geq 2,500 \mathrm{~g}$ & $109(50.5)$ & $14(12.8)$ & 28.0 & 0.000 \\
\hline $\mathrm{I}, 500-2,499 \mathrm{~g}$ & $71(32.9)$ & $14(19.7)$ & 28.0 & \\
\hline $1,000-1,499 \mathrm{~g}$ & $31(14.4)$ & $18(58.1)$ & 36.0 & \\
\hline$<\mathrm{I}, 000 \mathrm{~g}$ & $5(2.3)$ & $4(80.0)$ & 8.0 & \\
\hline \multicolumn{5}{|c|}{ Birth weight percentile for gestational age } \\
\hline$<10$ th & $32(14.8)$ & $3(9.4)$ & 6.0 & 0.076 \\
\hline$\geq 10$ th & $184(85.2)$ & $47(25.5)$ & 94.0 & \\
\hline \multicolumn{5}{|l|}{ Gestational age } \\
\hline$\geq 37$ weeks & $130(60.2)$ & $13(10.0)$ & 26.0 & 0.000 \\
\hline $32-36$ weeks & $62(28.7)$ & $20(32.3)$ & 40.0 & \\
\hline 28-3I weeks & $21(9.7)$ & $14(66.7)$ & 28.0 & \\
\hline$<28$ weeks & $3(1.4)$ & $3(100.0)$ & 6.0 & \\
\hline \multicolumn{5}{|c|}{ Duration of stay in the neonatal unit } \\
\hline Up to 3 days & $55(25.5)$ & $34(61.8)$ & 68.0 & 0.000 \\
\hline 4-7 days & $99(45.8)$ & $10(10.1)$ & 20.0 & \\
\hline$>7$ days & $62(28.7)$ & $6(9.7)$ & 12.0 & \\
\hline
\end{tabular}

Note: ${ }^{\text {aChi-square test. }}$

Abbreviations: SPHMMC, St Paul's Hospital Millennium Medical College; MAS, Meconium Aspiration Syndrome.
Bivariate analysis showed that the odds of death was higher in neonates who had gestational age (36.6 \pm 3.8 weeks) $(P=0.000)$, first-minute Apgar score $<7(P=0.000)$, fifthminute Apgar score $<7(P=0.000)$, need of ventilator support $(P=0.000)$, diagnosis of asphyxia $(P=0.012)$, absence of ANC $(P=0.026)$, and having fewer than four ANC visits $(P=0.007)$ by the mother during pregnancy. The risk of death was not significantly different for the other obstetric and clinical characteristics as shown in Table 2.

Binary logistic regression model was used to see factors associated with mortality. Variables that showed statistically significant association $(P$-value $<0.05)$ in the bivariate analysis were included in the model. Best fit model was obtained when the five variables (number of ANC visit, gestational age, presence of asphyxia, fifth-minute Apgar score, and firstminute Apgar score) were included in the model. Even though the three variables (history of ANC booking by the mother, need of ventilator support by the neonate, and duration of stay in the neonatal care unit) had statistically significant association in the bivariate analysis, we did not have logical CIs when they were included in the multivariate model. Hence, they were excluded from the final model. Because there was a significant correlation between gestational age and weight during admission ( $r=0.782$ ), only gestational age was used in multivariate analysis to avoid collinearity. Under multivariate analysis, diagnosis of asphyxia and gestational age less than the mean (36.6 weeks) were factors independently associated with mortality (Table 2).

\section{Discussion}

The aim of this study was to identify reasons for neonatal admission and causes of neonatal death in the neonatal care unit of a tertiary care center in Addis Ababa. Our finding that prematurity (36.6\%), sepsis (22.7\%), and asphyxia (16.2\%) were the most common factors for admission was consistent with the reports from other centers. ${ }^{12-14}$ The proportion of prematurity, sepsis, and asphyxia as causes of admission vary across different centers. In Tanzania, ${ }^{13}$ asphyxia, prematurity, and sepsis accounted for $26.8 \%, 18.4 \%$, and $15.4 \%$ of the causes of admission, respectively, where asphyxia and sepsis contributed a lesser proportion as a cause of admission when compared to ours. Also sepsis, prematurity, and asphyxia were described as major reasons for admission in Nigeria ${ }^{14}$ and Pakistan, ${ }^{15}$ the proportion accounted by each disease entity as a cause of admission varies across the centers. Sepsis and prematurity were also major causes of morbidity in another study in Nigeria. ${ }^{16}$ The fact that prematurity, sepsis, and asphyxia are being common causes of neonatal 
Table 2 Binary logistic regression estimates of the explanatory variables on neonatal mortality at SPHMMC, June 20I5 ( $\mathrm{n}=175$ )

\begin{tabular}{|c|c|c|c|c|}
\hline Variable & Death & $P$-value & COR $(95 \% \mathrm{Cl})$ & AOR $(95 \% \mathrm{Cl})$ \\
\hline \multicolumn{5}{|l|}{ Sex } \\
\hline Male & $33(66.0 \%)$ & & 1 & \\
\hline Female & $17(34.0 \%)$ & 0.419 & $0.76 \mid(0.393-1.476)$ & \\
\hline \multicolumn{5}{|l|}{ Age at admission after delivery } \\
\hline Within I hour & $30(60.0 \%)$ & & 1 & \\
\hline After I hour & 20 (40.0\%) & 0.245 & $0.683(0.359-1.298)$ & \\
\hline \multicolumn{5}{|l|}{ Mode of delivery } \\
\hline Spontaneous vaginal & $30(60.0 \%)$ & & 1 & \\
\hline Cesarean section or instrumental & $20(40.0 \%)$ & $0.47 \mathrm{I}$ & $0.789(0.4 \mid 5-1.502)$ & \\
\hline \multicolumn{5}{|l|}{ Place of delivery } \\
\hline Inborn & $43(86.0 \%)$ & & 1 & \\
\hline Outborn & $7(14.0 \%)$ & 0.397 & $0.682(0.28 I-\mid .655)$ & \\
\hline \multicolumn{5}{|l|}{ Gestational age } \\
\hline Less than the mean ( 36.6 weeks) & & & 1 & I \\
\hline Above the mean ( 36.6 weeks) & & 0.000 & $0.759(0.690-0.836)$ & $0.683(0.588-0.795)$ \\
\hline \multicolumn{5}{|l|}{ First-minute Apgar score } \\
\hline$<7$ & 35 (79.5\%) & & $3.776(1.687-8.454)$ & $1.742(0.548-5.542)$ \\
\hline$\geq 7$ & 9 (20.5\%) & 0.000 & 1 & 1 \\
\hline \multicolumn{5}{|l|}{ Fifth-minute Apgar score } \\
\hline$<7$ & $25(56.8 \%)$ & & $5.075(2.453-10.500)$ & $4.414(1.000-13.423)$ \\
\hline$\geq 7$ & $19(43.2 \%)$ & 0.000 & $\mathrm{I}$ & 1 \\
\hline \multicolumn{5}{|l|}{ Marital status of the mother } \\
\hline Married & 45 (90.0\%) & & 1 & \\
\hline Single or divorced or widowed & $5(10.0 \%)$ & 0.186 & $2.194(0.684-7.038)$ & \\
\hline \multicolumn{5}{|l|}{ Mother attended formal education } \\
\hline No & I3 (26.0\%) & & 1 & \\
\hline Yes & 37 (74.0\%) & 0.989 & $0.995(0.484-2.046)$ & \\
\hline \multicolumn{5}{|l|}{ Mother had antenatal care booking } \\
\hline No & $4(8.0 \%)$ & & 1 & \\
\hline Yes & 46 (92.0\%) & 0.026 & $0.140(0.025-0.790)$ & - \\
\hline \multicolumn{5}{|l|}{ Number of antenatal care visits } \\
\hline$<4$ & 37 (80.4\%) & & 1 & 1 \\
\hline$\geq 4$ & $9(19.6 \%)$ & 0.007 & $0.335(0.152-0.739)$ & $0.586(0.20 I-1.7 \mid 3)$ \\
\hline \multicolumn{5}{|l|}{ Pregnancy outcome } \\
\hline Singleton & $4 \mathrm{l}(82.0 \%)$ & & 1 & \\
\hline Twins & $9(18.0 \%)$ & 0.144 & $1.924(0.799-4.633)$ & \\
\hline \multicolumn{5}{|l|}{ Hypothermia at admission } \\
\hline No & 14 (28.0\%) & & $1.922(0.964-3.830)$ & \\
\hline Yes & $36(72.0 \%)$ & 0.063 & & \\
\hline \multicolumn{5}{|l|}{ Presence of asphyxia } \\
\hline No & $36(72.0 \%)$ & & 1 & I \\
\hline Yes & 14 (28.0\%) & 0.012 & $2.685(1.245-5.790)$ & $5.817(1.6 \mathrm{II}-20.997)$ \\
\hline \multicolumn{5}{|l|}{ Neonate needed ventilator support ${ }^{\mathrm{a}}$} \\
\hline No & $5(10.0 \%)$ & & I & \\
\hline Yes & $45(90.0 \%)$ & 0.000 & $105.923(35.84|-3| 3.045)$ & - \\
\hline \multicolumn{5}{|l|}{ Duration of stay in the neonatal unit ${ }^{\mathrm{a}}$} \\
\hline Up to 3 days & $34(68.0 \%)$ & 0.000 & 1 & \\
\hline 4-7 days & $10(20.0 \%)$ & 0.000 & $0.069(0.030-0.162)$ & - \\
\hline$>7$ days & $6(12.0 \%)$ & 0.000 & $0.066(0.024-0.180)$ & \\
\hline
\end{tabular}

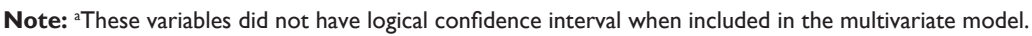

Abbreviations: SPHMMC, St Paul's Hospital Millennium Medical College; COR, crude odds ratio; Cl, confidence interval; AOR, adjusted odds ratio.

morbidity in neonatal care centers of developing countries including ours could imply the lack of appropriate interventions in the antenatal, intrapartum, and postpartum neonatal care. Sepsis occurs as a result of colonization of the neonate by bacteria in utero or after birth. This can be prevented by appropriate treatment of maternal infection and by proper infection prevention strategies during labor and delivery or after delivery. Asphyxia is a neonatal problem that can 
be prevented and should be prevented, but once it occurs reversing the damage to body organs may not be possible. Proper training of the health care provider on how to detect fetal jeopardy during labor and delivery and also on how to identify risk factors for asphyxia can help prevent asphyxia. Providing training on neonatal resuscitation to health care providers who attend labor and delivery is also very important in preventing asphyxia. Addressing some of the factors, which can lead to premature labor, could help to arrest preterm delivery. Hence, the fact that prematurity, sepsis, and asphyxia were common causes of admission in our center could imply the need to take appropriate measures to reduce these factors as cause of neonatal morbidity since some of the factors are preventable.

In our study, the majority of the neonates were inborn $(81.9 \%)$, and also they were admitted in their first hour of age postdelivery $(52.8 \%)$. In spite of these, most of them were hypothermic during admission (60.6\%), indicating the need for proper postdelivery care and improved neonatal transport in our setup. Previous study has shown hypothermia to be a major contributor to neonatal mortality. ${ }^{17}$

The overall mortality in our neonatal care unit was 50/216 (23.2\%). This magnitude was higher than the reports from some other centers. Previously, a lower mortality rate was reported in Tanzania ${ }^{13}(10.7 \%)$, Peshawar ${ }^{18}$ (8.3\%), East Timor $^{19}(11.4 \%)$, and Eritrea ${ }^{20}(8.2 \%)$, but a comparable magnitude of mortality with that of our finding was reported in Nigeria ${ }^{14}(19.4 \%)$. This difference in the magnitude of neonatal mortality across different neonatal care centers in the developing countries may reflect variation in the quality of service provided in the centers. But the higher magnitude of mortality in our center when compared to some of the centers mentioned earlier needs attention to improve the quality of care provided in the unit. According to the 2011 Ethiopian Demographic Health Survey, ${ }^{5}$ the magnitude of facility-based delivery and neonatal mortality in Addis Ababa was $82.3 \%$ and 21 deaths per 1,000 deliveries, respectively. In the midst of this lower rate of facility-based delivery in the city, the presence of higher neonatal mortality in our neonatal care unit could also be call for immediate action. The fact that our hospital is a tertiary care center may attract more pregnant mothers with obstetric complication for their delivery. However, in our study, we included both inborn and outborn babies, which could reflect the representativeness of our finding.

The leading causes of mortality in our neonatal care unit were prematurity $32 / 50(64 \%)$ and asphyxia 14/50
(28\%). The contribution of sepsis as a cause of neonatal death in our unit was low 2/50 (4\%). Studies conducted in other centers reported prematurity, asphyxia, and sepsis as major causes of mortality in a neonatal care unit. ${ }^{13,14,16,19}$ The high rate of mortality because of asphyxia in our finding is of particular interest since this is a preventable cause of neonatal death. Also the fact that prematurity was related to higher mortality in our neonatal unit may be related to the lack of appropriate treatment modalities, such as mechanical ventilation, surfactant administration, and parenteral nutrition.

The strengths of the current study included its being prospective in design, which allowed for better control over data acquisition. The fact that the study was done in one of the most resource limited settings will help planners for better resource allocation and optimize the local resources for better care. The findings would specifically be of interest for similar settings in resource-limited countries. The limitations include its representativeness because of its hospital-based nature and short follow-up period.

\section{Conclusion}

In conclusion, a quarter of the studied neonates died in the unit. Asphyxia and prematurity were the major causes of admission and mortality. Based on our findings, we suggest that the local and national stakeholders revisit and restructure the strategies set in place for preventing asphyxia and prematurity and also in strengthening a better facility for skin-to-skin care for preterm babies and managing babies with asphyxia. The findings also indicate that more contextspecific operational and qualitative studies should be done to identify the causes of asphyxia, such as sociocultural issues, and subsequently on the prevention strategies.

\section{Acknowledgments}

We would like to thank St Paul's Hospital Millennium Medical College for funding this research project. We would also like to extend our appreciation to our data collectors and the participants of the study. Our heartfelt gratitude has to go to Dr Khalid Aziz who has done copyediting of this article.

\section{Author contributions}

All the authors participated in writing the proposal, data collection and analysis, writing the article, gave final approval of the version to be published, and agree to be accountable for all aspects of the work. Additionally, Atnafu Mekonnen Tekleab did the conception and data analysis. 


\section{Disclosure}

The authors report no conflicts of interest in this work.

\section{References}

1. Lawn JE, Cousens S, Zupan J. Lancet Neonatal Survival Steering Team. 4 million neonatal deaths: when? Where? Why? (Abstract). Lancet. 2005;365(9462):891-900.

2. Rajaratnam JK, Marcus JR, Flaxman AD, et al. Neonatal, post neonatal, childhood and under-5 mortality for 187 countries, 1970-2010: a systematic analysis of progress towards millennium development goal 4 (Abstract). Lancet. 2010;375(9730):1988-2008.

3. Lawn JE, Blencowe H, Oza S, et al; Lancet Every Newborn Study Group. Every newborn: progress, priorities, and potential beyond survival (Abstract). Lancet. 2014;384(9938):189-205.

4. Mekonnen Y, Tensou B, Telake DS, Degefie T, Bekele A. Neonatal mortality in Ethiopia: trends and determinants. BMC Public Health. 2013;13:483.

5. Central Statistical Agency [Ethiopia]; ICF International. Ethiopia Demographic and Health Survey 2011. Addis Ababa, Ethiopia; Calverton, MD, USA: Central Statistical Agency and ICF International; 2012.

6. McClure EM, Wright LL, Carlo WA, Chakraborty H, Harris H. Effect of WHO newborn care training on neonatal mortality by education. Ambul Pediatr. 2008;8(5):300-304.

7. Lawn JE, Kerber K, Enweronu-Laryea C, Massee Bateman O. Newborn survival in low resource settings - are we delivering? BJOG. 2009;116(suppl 1):49-59.

8. Ballard JL, Khoury JC, Weding K, Wang L, Eilers-Walsman BL, Lipp R. New Ballard score, expanded to include extremely premature infants. J Pediatr. 1991;119:417-423.

9. Morales P, Bustamante D, Espina-Marchant P, et al. Pathophysiology of perinatal asphyxia: can we predict and improve individual outcomes? EPMA J. 2011;2(2):211-230.
10. Hermansen CL, Lorah KN. Respiratory distress in the new born. $A m$ Fam Physician. 2007;76(7):987-994.

11. American Academy of Pediatrics Subcommittee on Hyperbilirubinemia. Management of hyperbilirubinemia in the newborn infant 35 or more weeks of gestation. Pediatrics. 2004;114:297.

12. Mukhtar-Yola M, Iliyasu Z. A review of neonatal morbidity and mortality in Aminu Kano Teaching Hospital, northern Nigeria. Trop Doct. 2007;37(3):130-132.

13. Mmbaga BT, Lie RT, Olomi R, Mahande MJ, Kvåle G, Daltveit AK. Cause-specific neonatal mortality in a neonatal care unit in Northern Tanzania: a registry based cohort study. BMC Pediatr. 2012;12:116.

14. Toma OO, Ige OO, Abok II, Onwuanaku C, Abah RO, Donli A. Pattern of neonatal admissions and outcome in a tertiary institution in north central Nigeria (Abstract). J Med Trop. 2013;15(2):121-125.

15. Ali SR, Ahmed S, Lohana H. Disease patterns and outcomes of neonatal admissions at a secondary care hospital in Pakistan. Sultan Qaboos Univ Med J. 2013;13(3):424-428.

16. Ahmadu BU, Babba HI, Abdallah JA, et al. Neonatal Morbidity and Mortality Trend in a Special Care Baby Unit of a Tertiary Hospital in Yola: the need to educate health workers and mothers on quality neonatal health practices. Am J Health Res. 2013;1(3):99-103.

17. Haws RA, Thomas AL, Bhutta ZA, Darmstadt GL. Impact of packaged interventions on neonatal health: a review of the evidence. Health Policy Plan. 2007;22:193-215.

18. Jan AZ, Ahmed S, Zahid SB. Clinical audit of admission pattern and its outcome in a Neonatal ICU. Gomal J Med Sci. 2013;11:31-36.

19. Bucens IK, Reid A, Barreto AC, Dwivedi V, Counahan M. years of neonatal morbidity and mortality at the national hospital in Dili, East Timor. J Paediatr Child Health. 2013;49(6):452-457.

20. Shah S, Zemichael O, Meng HD. Factors associated with mortality and length of stay in hospitalised neonates in Eritrea, Africa: a crosssectional study. BMJ Open. 2012;2:e000792.
Research and Reports in Neonatology

\section{Publish your work in this journal}

Research and Reports in Neonatology is an international, peer-reviewed, open access journal publishing original research, reports, editorials, reviews and commentaries on neonatal health. The manuscript management system is completely online and includes a very quick and fair

\section{Dovepress}

peer-review system. Visit http://www.dovepress.com/testimonials.php to read real quotes from published authors. 